\title{
What drives you to check in on Facebook? Motivations, privacy concerns, and mobile phone involvement for location-based information sharing
}

Hyang-Sook Kim

Department of Mass Communication \& Communication Studies, Towson University, 132 Stephens Annex, 8000 York Road, Towson, MD 21252, USA

\section{Abstract}

Given the popularity of checking in at a location via mobile phone, little research has examined the germane motivations tied to location check-in as a form of in-group electronic word-of-mouth and its relation to the concern of privacy. A survey with 255 college students found that the students' privacy concerns - both online and Facebook specific - did not show any relationship with the motivations of location check-in as a means of information sharing. However, the relationship varied among the non-users of location check-in on Facebook. Involvement with mobile phone showed mixed relationships with check-in motivations - commitment to Facebook, self-development and reputation, and promotional viral communication. Findings not only confirm that young Facebook users are relatively free from the concern of privacy during their location-based information sharing, but also suggest different motivational mechanisms to operate for Facebook users' viral communication depending on the habitualness of their mobile phone use. Implications are discussed for interpersonal marketing strategies on social networking sites.

Keywords

Location-based information sharing; Facebook check-in motivations; Online privacy; Mobile phone involvement

\section{Introduction}

Mobile checking in is one of the top ten mobile activities among adults who go online with their cell phones (Pew Internet Research, 2013). With the rapid growth of the number of mobile users, location-based information sharing(LBIS) has become a savvy trend in the space of social networks. Several recent studies have documented mobile phone users' intention to engage in LBIS (e.g., Chang \& Chen, 2014; Lindqvist, 
Cranshaw, Wiese, Hong, \& Zimmerman, 2011) along with the effects of user characteristics that include personal traits such as extroversion/introversion as well as cultural orientation on intention of LBIS(e.g., Chen \& Marcus, 2012; Gilbert \& Barton, 2013; Wang, 2013). Besides these studies regarding behavioral intention and the effects of individual differences on mobile check-in, little research has explored the predictors of user behavior of LBIS in terms of motivational factors that drive such behavior beyond the scope of selfpresentation on social networking sites (SNS) (e.g., Wang, 2013) or a technological utility approach (e.g., Bilogrevic, Huguenin, Mihaila, Shokri, \& Hubaux, 2015).

While actively broadcasting where they are, mobile users typically encounter concerns regarding privacy entrenchment as a result of LBIS (e.g., Pontes, Vasconcelos, Almeida, Kumaraguru, \& Almeida, 2012). Previous literature has investigated users' perceived threats of privacy information leaking when they socially display their activities on SNS such as Facebook.com (e.g., Chang \& Heo, 2014; Waters \& Ackerman, 2011; Christofides, Muise, \& Desmarais, 2009; Ljepava, Orr, Locke, \& Ross, 2013; Taddicken, 2014). Contrary to expectations, most of the studies found little connection between the intention of self-disclosure and apprehension ofleaking their private information on Facebook (e.g., Christofides et al., 2009). People do not mind risking their privacy in order to exhibit their activities on SNS, especially when they trust SNS (Waters \& Ackerman, 2011), because they perceive the access to such information to be limited only within the network that they defined (Taddicken, 2014).

Then, are people still willing to take the risk from the potential privacy threats when they share their locations with others beyond simple self-presentation? This question apparently adds another layer of the privacy issue to the personal space of Facebook in relation to LBIS. The nature of LBIS might be unique compared to other generic SNS activities, such as posting on walls or sharing photos, which typically cater to users' selfpresentational motivation. The feature of LBIS on Facebook, called "Check-In," typically does require less time devotion than the general posting activity on walls. Furthermore, one distinct characteristic of LBIS on Facebook is it classification for public information sharing with a promotional purpose (Wilson, 2012). As the most famous check-in locations are all types of businesses including transportation services, scenic areas, hotels, etc. (Noulas, Scellato, Mascolo, \& Pontil, 2011), LBIS pertains to a means of viral communication with marketing impacts, since it most often involves some level of business. Although LBIS deems the designated impact of viral communication on closed networks if it happened on Facebook, this particular in-group electronic word-of-mouth (eWOM) cannot be overlooked in terms of (in)direct promotional strategies, considering the powerful effect from the familiar source of the information (Hung, Li, \& Tse, 2011; Wathen \& Burkell, 2002).

Given these characteristics of LBIS that encompass activities of generic SNS and eWOM, motivations to check in via mobile devices might be different from general Facebook use motivations such as self-presentation, social connectedness, and memory storage for the self. Thus, the present study aimed to examine user motivations of the use of location checking in on Facebook more often as a method of information sharing and eWOM than self-presentation followed by the relationship between those motivations and the concern of privacy invasion, since LBIS allows users to 'share' their locations at a moment, which essentially holds some level of threat for crimes or other unwanted outcomes (Young, 2000; Lindqvist et al., 2011).

\section{Literature review}

\section{Motivations for location-based information sharing (LBIS)}

Location-based services (LBS) are defined as "a subset of web services meant to provide functions that are 
location-aware, where the use of such services is predicated on knowledge of where the services are engaged" (Wilson, 2012, p. 1267). It is rather simple to share information via LBS mobile applications compared to other forms of information sharing, such as posting on SNS, online message boards, and blogs. Despite the simplicity of the action, the impact of LBIS is not trivial, because it operates not only as a means of information dissemination but also for ego-oriented psychology that gratifies self-identity (Wang, 2013).

Previous studies treated LBIS as the same means of self-expression and self-disclosure performed on a popular SNS platform such as Facebook.com. Reviewing literature of self-presentations for one's identity and sociality construction, Wang and Stefanone (2013) conceptualized Facebook check-in as a tool for impression management. They argued that "presentation of place" (p. 440) eventually would facilitate and satisfy one's desire to be connected to other people online using a certain image of the person(i.e., offline social lifestyle). Therefore, this particular type of self-disclosure on Facebook would be highly correlated with one's personality traits, such as extroversion and narcissism, which would lead to the person's checkin behavior. The findings of their study confirmed the theoretical path from one's extroverted, outgoing personality to check-in intensity via the degree of self-disclosure on Facebook and the person's preference for showing off (i.e., exhibitionism) (Wang \& Stefanone, 2013). Wang (2013) also found a similar theoretical path that explained the intensity of check-in as a result of disclosing and sharing one's activities on Facebook based on the person's outgoing personality. In addition, the role of overall life satisfaction increased one's check-in intensity, although in a small degree of standardized coefficient (.10). Therefore, people are willing to display their activities in an online social space when (1) their personality prefers such behavior and (2) they believe their life is pleasant enough to show off to their friends on Facebook. However, it is not clear that these findings can also infer that the motivations for self-disclose on Facebook are identical to those for sharing location information with friends on Facebook with a promotional purpose or similar motivation.

The check-in as an action of sharing information may need further speculation in terms of what exactly drives people to check in. Some of the previous works on photo sharing and tagging might offer insight into this conceptualization task. With a basis of understanding social-computing communities, Nov, Naaman, and Ye (2009) developed four distinct dimensions of motivations to share, annotate, and tag photos on Flickr. Flickr is "an online community and artifact-sharing system in which content is created, shared, annotated, and viewed by users" (p. 3). Two distinct characteristics of Flickr compared to Facebook are as follows: first, the action users perform in the Flickr interface is rather simple (i.e., uploading photos or tagging photos), and second, not all users are "friending" each other. Given the pertinent nature of Flickr as an online community for visual information sharing, Nov et al. (2009) identified user motivations for Flickr in four dimensions enjoyment, commitment to the community, self-development, and reputation building.

These four dimensions may serve as motivations for location check-in as well in that checking in at locations is a voluntary action of information sharing. Such self-initiated action inherently aims at practicing one's capability to contribute to a community along with expectations of increasing popularity as well as expertise (Sundar, 2008; Kim \& Sundar, 2011). In fact, Lindqvist et al. (2011) found that people checked in at their location via Foursquare in order to pursue continued connection with friends, to enjoy the sharing of their locations, and finally to explore new places for their own experiences. An earlier work by Ames and Naaman (2007) also suggested that even information sharing in the domain of Flickr would have two conspicuous purposes: functional and social. People upload visual information not only for their own future use, like wireless digital albums, but also for a means of contribution to the community along with gaining popularity. Likewise, as a form of information sharing, location check-in might be articulated by similar motivations of visual information sharing, namely enjoyment, commitment to the community, self- 
development, and reputation building.

\section{Location-based information sharing as electronic word-of-mouth}

It is undeniable that Facebook check-in is an extension of one's self-presentation online. This variation of self-presentation, however, encodes the unique meanings of locations beyond one's exuding personal sentiments. Noulas et al. (2011) found that most famous check-in locations included a certain type of business, such as transportation services, scenic areas, and hotels. Previous research on online viral communication has revealed how people share product and service information with other potential consumers, which influence one's purchase decision-making process (Gruen, Osmonbekov, \& Czaplewski, 2006). eWOM is defined as "any positive or negative statement made by potential, actual, or former customers about a product or company, which is made available to a multitude of people via the Internet" (Hennig-Thurau, Gwinner, Walsh, \& Gremler, 2004, p. 39). One might argue that the final destination of the eWOM is not completely public, but limits other users' access on the space of Facebook compared to the classic eWOM platform, namely the Internet. However, the viral nature of communication is inherent to LBIS, as is eWOM, because location-based information tells other potential customers about one's impressions and instant evaluation on the places the person visits or has visited. Therefore, the function of spreading words of businesses is an integral part of the location check-in even on Facebook. In particular, the algorithm of Facebook Places (i.e., an aggregated information platform of location check-in via users' mobile devices on Facebook) has an element that prepares an information infrastructure from the user's end such that when one user registers a location which is not listed on the existing system of Places, that users' initiation of place tagging will become available to other users, even outside of that person's network. This option for location tagging is similar to earlier information tagging structures happening in most social computing and cloud-sourcing (Morrison, 2008; Nakamoto et al., 2008). Commercialization of location check-in indeed comes into play (Wilson, 2012, p. 1272).

Some earlier work on microblogging has applied eWOM to social media use. Jansen, Zhang, Sobel, and Chowdury (2009) found that a significant number of Twitter users mentioned brand names in their tweets, which mostly contained short evaluations of products and services. In fact, Jeong and Jang (2011) found that eWOM occurred more often when people had pleasant experiences with businesses and services than when they had mundane or unpleasant experiences with those places. In addition, Steffes and Burgee (2008) found that eWOM from familiar sources, like friends, would be more powerful than that from random sources. If this were the case in the location check-in on Facebook, the impact of location check-in would be beneficial to businesses. Likewise, it is important to scrutinize motivations tied to location check-in on Facebook in the context of eWOM, because relationship strength is one of the critical factors that determine the effectiveness of eWOM to one's purchase decision making.

Previous literature in eWOM investigated why people would engage in viral communication (e.g., HennigThurau et al, 2004; Hennig-Thurau \& Walsh, 2003; C.-C. Huang, Lin, \& Lin, 2009; Sun, Youn, Wu, \& Kuntaraporn, 2006). Phelps, Lewis, Mobilio, Perry, and Raman (2004) conducted a series of explanatory studies combining qualitative and quantitative research methods to explore the motivations and needs among people engaging in viral communication. They found that people forward viral messages (i.e., pass along emails) because it is fun, enjoyable, entertaining, and benevolent, and it makes them feel connected to others. Hennig-Thurau et al. (2004) developed eight dimensions of eWOM motivations, namely "platform assistance, venting negative feelings, concern for other consumers, extraversion/positive selfenhancement, social benefits, economic incentives, helping the company, and advice seeking” (p. 48). Hennig-Thurau et al. (2004) found that concerns for other consumers, extraversion/positive selfenhancement, social benefits, and economic incentives predicted one's actual eWOM activity. Thus, 
location check-in motivations might expect similar results except the dimension of extrinsic incentives, which can be replaced with psychological rewards as a result of self-disclosure and self-presentation on Facebook.

\section{Privacy and location-based information sharing}

Although it is not entirely public and prescribed within one's personal, verified network, LBIS still deems the issue of potential privacy invasion (Ames \& Naaman, 2007). Privacy is defined as "the feeling that one has the right to own private information, either personally or collectively" (Petronio, 2002, p. 6). Communication privacy management theory posits that people tend to be either afraid of or comfortable with disclosing personal information depending on (1) the level of intimacy between them and those who will access the information, (2) the degree of public accessibility to the information, (3) their level of control over the private information, (4) the degree of stability of the system where the information is disclosed and possibly shared, and lastly (5) the degree of tension between what will be kept and what will be disclosed (Petronio, 2002, 2007). Aligned with the theoretical assumptions, a body of literature that examined users' perceived entrenching of privacy on Facebook found that (1) control over the information to be shared, (2) the level of trust with the platform where the information might be shared, and (3) prior experience with the platform would cancel out the perceived privacy invasion and related concerns (Waters \& Ackerman, 2011). In other words, information disclosure is not always negatively correlated with privacy concern (Christofides et al., 2009). When people trusted a website, they typically disclosed more information than when they did not (Dwyer, Hiltz, \& Passerini, 2007). Given the voluntary nature of information disclosure on Facebook, users who did not use Facebook often showed less intention to disclose private information than did frequent users (Ljepava et al., 2013).

Previous literature has specifically documented concerns, particularly surrounding LBIS, through a physical measure of privacy leaking. Pontes et al. (2012) expected that people might have grave concern about a stranger tracking down information about users' residency based on the information available on Foursquare. However, the actual perceived level of private information leaking among users was not as high as they anticipated. This would be truer on Facebook than other location-based service applications like Foursquare, because of the limited access to the location information depending on a user's control over the privacy setting on Facebook. Taddicken (2014) found no relationship between privacy and self-disclosure because of the low possibility of public access to their information on Facebook.

The degree of one's privacy concern can be determined by the level of sensitivity of the information to be shared. Chang and Heo (2014) found that people exhibited greater sensitivity toward topics to be shared on Facebook when they had more experience with Facebook and perceived more benefit from the use of the Facebook than when they did not. However, the perceived risk potentially occurring as a result of Facebook use was not significant to these Facebook users. They even exhibited strong trust toward Facebook, as they were still sensible of the topics to be shared. Thus, when people perceived benefits by satisfying their original motivations to share location information on Facebook, they would not mind trading private information, especially when the location information is not highly confidential but they are rather willing to share it with others. Furthermore, Facebook users may not have much risk perception on the Facebook domain when they are already used to the site and had experience with location check-in.

Taken together with findings from the previous literature, the following hypotheses are formulated.

H1a: The more privacy concerns people show, the fewer check-in motivations they show. $\mathrm{H} 1 \mathrm{~b}$ : The more privacy concerns people show, the less likely they are to check in at 
locations on Facebook.

H2a: People who have checked in at locations on Facebook have fewer privacy concerns than those who have not engaged in such an activity.

H2b: People who have checked in at locations on Facebook have more motivations to check in than those who have not engaged in such an activity.

$\mathrm{H} 2 \mathrm{c}$ : The more check-in motivations people show, the more likely they are to check in at locations on Facebook.

\section{Mindless use of mobile phone and location-based information sharing}

As mentioned earlier, familiarity with the interface and habitualness of the action is one possible explanation of why people may not raise a red flag regarding privacy on Facebook, even when they share their location information. Previous studies suggest that privacy concerns would be cancelled out when users spend a lot of time on Facebook. This is particularly true among those in young generations, some of whom might be considered addicted, especially to mobile phone use (Bianchi \& Phillips, 2005; Pew Internet Research, 2013). Brandtzæg, Lüders, and Skjetne (2010) found that young people's ready adoption of privacy settings on Facebook attenuated their privacy concern compared to those of older generations and led them to share more about themselves on Facebook. Hugl (2011) also suggested a significant role of age in altering the privacy concern in SNS. Generally, the younger the user, the less the privacy concern.

Walsh, White, and Young (2010) examined how young adults' expectation toward their self-image as a result of mobile phone use influenced their actual involvement with the mobile phone. They found that such self-image was a significant predictor of young adults' mobile phone involvement. In addition, young adults' expectation toward validation from other people was also a significant predictor of their mobile phone involvement. These findings imply that one's mobile phone involvement is strongly connected to Facebook activities for self-presentation and social-connectedness because mobile phone involvement is an indicator of habitual and mindless use of the phone in one's everyday life.

H3a: The more involved with mobile phone use people are, the fewer online privacy concerns they have.

$\mathrm{H} 3 \mathrm{~b}$ : The more involved with mobile phone use people are, the greater number of checkin motivations they exhibit.

$\mathrm{H} 3 \mathrm{c}:$ The more involved with mobile phone use people are, the more they check in at locations on Facebook.

\section{Method}

\section{Participants and procedures}

Initially, 283 college students participated in an online survey. Upon the completion of the survey, the students received extra credit as compensation for their participation. A total of 255 usable samples were saved for the analysis after exclusion of the student data that indicated no awareness of Facebook check-in $(n=28)$. The final sample for the data analysis consisted of $51 \%$ females, and the mean age of the sample was 20 years old. White was the most dominant race, comprising $85 \%$ of the sample. Students in the communication and media studies major participated in the survey at the highest rates (40\%), followed by business and economics (18\%) and education (7\%). Students reported that they spent $4.4 \mathrm{~h}(S D=3.63)$ on average per day engaged in cell phone use, and $1.7 \mathrm{~h}(S D=1.89)$ were solely allocated to check Facebook. 


\section{Measures}

The present study used 7-point scales for all measures except a selection of the measures for Facebook use, check-in experience, and demographic information. All items in the following measures are listed in the Appendix.

Facebook check-in motivations were measured using two different scales adopted and modified from Nov et al.'s photo sharing and tagging motivations (2009) and the eWOM motivations applied by HennigThurau et al. (2004). Although several previous studies used motivation scales for self-disclosure and exhibitionism for Facebook use in general (e.g., Wang, 2013; Wang \& Stefanone, 2013), those scales do not fully represent the nature of location check-in as information sharing. Furthermore, since the present study conceptualized location check-in as a form of eWOM, motivations for eWOM also need to be examined in this particular context of information sharing action. All 13 items of photo sharing and tagging motivations were modified for the present study (Nov et al., 2009). A principal components analysis revealed three dimensions of motivations: enjoyment $(\alpha=.92)$, commitment $(\alpha=.81)$, and a combination of selfdevelopment and reputation building (a .96). Another check-in motivation scale was adopted and modified from the eWOM motivation scale by Henning-Thurau et al. (2004). The current study utilized only 10 items selected from the original 27-item scale, which were adequately operationalized for checking-in activity for the sake of face validity. A principal components analysis found no distinction emerging from the scale, which allowed the current study to combine all 10 items to create a motivation variable, labeled as promotional agency for the main data analysis (a .95).

Two sets of privacy concern measures were adopted for the current study. The general online privacy concern (Chellappa \& Sin, 2005) measured users' psychological apprehension about privacy invasion and misuse of private information in the context of various personalization services online $(\alpha=.83)$. Under speculation of different nuances of privacy concern due to one's control over privacy settings on Facebook, the current study also measured students' privacy concerns, particularly pertaining to Facebook use as well (Facebook privacy concern, $\alpha=$.84) (Baek \& Morimoto, 2012). Mobile phone involvement was adopted from Walsh et al. (2010). Eight items asked students to what extent they were engaged in mobile phone use, both in mindful and mindless manners, and how uncomfortable they would feel if they were not able to use their mobile phone $(\alpha=.84)$.

Students' experience with Facebook check-in along with their perceived frequency of check-in was also measured if they answered "yes" to the actual experience. The actual experience with check-in was used to classify two different user groups for the main analysis to test the second set of hypotheses. General demographic information was also gathered at the end of the questionnaire. A series of regression analyses, binary logistic regression, and independent samples t-tests were performed to test the hypotheses. Neither problematic skewness of data distributions nor multicollinearity among predictors of regression analyses was found. Means and standard deviations of main variables are reported in Table A.1.

\section{Results}

Data with 255 students revealed that privacy concerns regarding online activity in general did not show any relationship with four LBIS motivations. However, it predicted students' having less enjoyment with LBIS ( $\beta=$ $-.20, p<.10)$ and being unlikely to be a promotional agency via LBIS $(\beta=-34, p<.05)$ only for those who had not shared location information on Facebook before. Privacy concerns regarding Facebook in particular positively predicted the promotional purpose of LBIS regardless of the prior experience with LBIS (see Table A.2.). Thus, $\mathrm{H} 1$ received partial support from the present data. For $\mathrm{H} 2 \mathrm{a}$, the data found no statistical difference between prior users and non-users in their online privacy concerns both in general and on Facebook, thus failing 
to support the hypothesis. However, the prior LBIS users on Facebook showed greater levels of all four LBIS motivations measured in the study than those who had not used LBIS on Facebook before. Thus, H2b was supported (see Table A.3).

Positive correlations between mobile phone involvement and privacy concerns in general $(r=.21)$ and on Facebook $(r=.18)$ were found among those who had not checked in at locations on Facebook before, while a marginally significant positive correlation between the mobile phone involvement and general online privacy concerns was found among those who had prior experience with LBIS $(r=.12)$. Thus, the data did not support H3a (Table A.1.). Students' mobile phone involvement positively predicted LBIS motivations except the enjoyment motivation. In particular, students' prior experiencewith LBIS did not matter as much to the increase of commitment motivation as their mobile phone dependency, while the other two motivations - self development/reputation and promotional agency - showed different results depending on students' prior experience with LBIS (Table A.2.). Thus, H3b received partial support.

Lastly, logistic regression analysis found that students' online privacy concerns on Facebook in particular would prevent their LBIS activity $(\beta=-.22)$, while general online privacy concerns did not show any relationship with the likelihood of LBIS activity. Thus, H1b received partial support. Among the four LBIS motivations examined in this study, the promotional agency motivation highly predicted the likelihood of LBIS activity among college students $(\beta=.70)$. Mobile phone involvement also positively predicted students' likelihood of LBIS on Facebook $(\beta=.45)$. Thus, H2c received partial support while H3c was supported by the study data (Table A.4).

\section{Discussion}

"Conspicuous mobility" has become part of people's SNS lifestyles by leaving their traces in online spaces (Wilson, 2012,p. 1266). Previous studies have investigated the motivations of checking in at a given location in the scope of self-presentation under the influence of some of the individual difference traits (e.g., Wang, 2013; Wang \& Stefanone, 2013). The present study situated motivations of LBIS on SNS in the context of simple tagging and in-group eWOM based on the user action afforded by geo-tagging technology. This technology allows users to extend their Facebook space from solely self-oriented SNS activities such as changing profile pictures and posting on walls to community contribution in the form of sharing location information. With this new approach to conceptualizing the location check-in, the current study aimed at examining the relationship between check-in motivations and people's privacy concerns as the previous studies articulated the interesting dynamics of people's worries about disclosing their personal information online (e.g., Waters \& Ackerman, 2011).

\section{The mechanism of uncertainty reduction for privacy concerns with location check-in}

On the surface level, the present study found similar results to those of the previous studies (e.g., Ljepava et al., 2013; Waters \& Ackerman, 2011) in that no significant relationships were found between user privacy concerns - both general and Facebook specific - and check-in motivations (Table A.2). However, the results depended on students' prior experience with LBIS on Facebook, although no difference was found between LBIS users and non-users with regard to privacy concerns online in general and on Facebook specific. Those who had not shared locations on Facebook showed fewer degrees of LBIS motivations (enjoyment and promotional agency factors). Aligned with these findings, the study also found a negative relationship between the privacy concerns on Facebook and students' LBIS activity. The findings of the present study also suggest that students' involvement with their mobile phone could increase their self-alert to online privacy. This vigilance toward online privacy 
among those who highly engage in mobile phone use on a daily basis was prominent among those who had prior experience with LBIS. Mobile phone involvement appears to be a significant predictor of LBIS motivations, especially for the commitment motivation sector. It also could increase the likelihood of LBIS activity itself.

Accordingly, the relationships among a set of primary variables examined in the present study imply that, first, online privacy concerns on Facebook are distinctive from general online privacy concerns among college students when this issue of privacy comes into play with LBIS on Facebook. Second, familiarity with LBIS and mobile use dependency exhibited by mobile phone involvement would change dynamics of LBIS motivations and actual LBIS action on Facebook. Previous literature suggests that privacy concerns may still not be prominent as long as the level of accessibility to private information is limited in spite of the greater number of potential risks of displaying location information than personal reflection and lifestyles only (Taddicken, 2014). This general tendency might be still true of those Facebook users who share their location information. To these LBIS users on Facebook, the perceived threat to their information privacy was possibly low, as the operationalization of self-presentation and promotional motivations adopted from the eWOM motivation scale (Hennig-Thurau et al., 2004) indicated that Facebook activity, including location check-in, inherently confined the boundary of their information disclosure to a known network only (see Appendix). However, this tendency was not found among non-users of LBIS, as they exhibited less motivation to share location information and less likelihood of LBIS activity.

This soft versus hard shell to break privacy concerns among LBIS users and non-users, respectively, might be attributed to the different degree of uncertainty toward consequences of LBIS. Zhang and Leung (2014) suggested that prominent cues for potential privacy issues should not be given in the SNS interface; otherwise, users would be sensitive to warning signs that might threaten their private information and personal offline space immediately. Likewise, the high familiarity with Facebook space among the students was likely to reduce the level of uncertainty regarding the likelihood that their private information would be used by others. This kin relationship between the familiarity with the privacy settings of Facebook and the degree of personal information disclosure reduces the level of uncertainty in their actions and that of trust with sites, which in turn, lowers the threshold but increases one's willingness to give away personal information (Dwyer et al., 2007; Waters \& Ackerman, 2011).

In addition, people do not mind trading their personal information for benefits that may exist (Beldad, Jong, \& Steehouder, 2011; Chang \& Heo, 2014). Yun, Han, and Lee (2013) found that people with a low level of information privacy concern reported a greater intention to use the service because of the perceived benefits in the context of use of the location-based services such as Foursquare. In other words, the perceived privacy threats among Facebook users depends on their familiarity and trust with the virtual space, which in turn would determine the willingness to disclose personal information, including their realtime locations. Thus, Facebook privacy concerns positively - not negatively (or even no relationship at all) - predicted the promotional agency motivation among those who have shared location information on Facebook before (Table A.2). This result might also be attributed to people's psychological tendency of the "not me, but them" effect. Debatin, Lovejoy, Horn, and Hughes (2009) suggested that people enjoyed their SNS activities without much concern for privacy invasion because they perceived that the privacy invasion would be likely to happen to other users only. This third-person effect (Perloff, 2009) may make students less conscious of privacy concern while sharing their location information for the purpose of in-group eWOM (Paradise \& Sullivan, 2012).

Furthermore, high involvement with mobile phone use on a daily basis showed a negative relationship with the privacy concern regarding disclosing information on Facebook for those who had not shared location 
information on Facebook before (Table A.1). It is highly plausible that the more students were involved with their mobile phone on a daily basis, the more they were concerned about their privacy online. However, this was not the case with Facebook users who had used the LBIS feature before. These LBIS users were already familiar with the privacy settings of Facebook, as they spent a sufficient amount of time with the mobile phone and Facebook. In fact, Brandtzæg et al. (2010) found that the younger generation's ready adoption of the privacy settings on Facebook compared to older generations eventually made younger users detached from the worries about privacy when their Facebook activities became a daily habit (Hugl, 2011). Thus, the finding of the present study adds another piece of evidence that demonstrates the conditional interpretation of privacy entrenchment among SNS users, especially in context of this particular activity of location check-in.

\section{Impacts of habitual use of mobile phone on motivations of Facebook location check-in}

College-aged students compose the primary group of the generation of technology-savvy called Millennials (Pew Research Center, 2010). Their high involvement with mobile phones on a daily basis is one of the typical lifestyle features of this generation. Considering this generation of Millennials, one of the primary user groups of location check-ins including Facebook Check In, individual characteristics concerning mobile phone use is key to understand the motivations of the user action of sharing their location information. The current study found that habitualness of mobile phone use would increase motivations to engage in the location check-in activity, especially the commitment motivation (Table A.2.). It is very likely that Facebook users develop their positive motivations to share location information on Facebook as they consistently heavily rely on their smartphones. Even without prior experience, such high dependence on smartphones would increase the motivations of fidelity to share location information and promotional purpose of sharing location information on Facebook (Table A.2). The high level of knowledge about the mobile device for a myriad of activities, including location check-in, could positively influence LBIS because of the effect of learning the mobile device through constant use. Huang and Hsu (2013) found that perceived ease of use was one of the contributing factors to a positive attitude toward location check-ins. Therefore, it is likely that the more time Facebook users spend on their smartphones, the greater the motivations to engage in location check-in as a positive result of the cumulative instrument learning.

\section{Location check-in as a promotional strategy for business on Facebook}

It is well known that viral communication has powerful impacts on business (e.g., Amblee \& Bui, 2011; Huang et al., 2009). LBIS via simple location tagging and often with short evaluations on the place to be tagged on Facebook feeds would be much stronger than happens in open, public virtual spaces because of not only low risks of privacy leakage to unknown groups (Waters \& Ackerman, 2011) but also trust toward the information posted by acquaintances, namely Facebook friends (Steffes \& Burgee, 2008). Therefore, LBIS on Facebook calls for attention of businesses that have been relying on social media advertising.

In this sense, for those businesses and social media advertisers, one finding of the present study implies that students' prior experience made a difference in their check-in motivations (Table A.3). Previous literature documented that prior experience in the form of involvement with user activity has been identified as a critical factor to alter one's motivation to share information. Nov et al. (2009) found that membership history moderated the relationship between self-development and commitment motivations and the actual amount of photo sharing, such that people who maintained a longer membership with strong self-development and commitment motivations shared more photos than those who recently joined the community. Since checking in on Facebook is an "in-group" eWOM activity, it pursues group members' validation, which can happen only after actual check-in has taken place. Lam and Mizerski (2005) suggested the importance of the other 
groups' validation in boosting eWOM activity within a group network. Therefore, it is possible that students who have checked in on Facebook receive "Likes" from their friends, which essentially serves as others' validation. This in-group validation in the form of community feedback would be a good call for the future study. The strong relationship between the promotional agency motivation and actual likelihood of LBIS on Facebook (Table A.4.) further emphasizes the potential of indirect, interpersonal advertising effects of LBIS.

Therefore, social media advertisers want to develop their strategies offline that promote Facebook users' LBIS (e.g., offline incentives such as instant discount coupons) so that Facebook users can initiate LBIS via Check In, which possibly helps the users continue to engage in LBIS. As noted earlier, the simplicity of the action for LBIS via Facebook Check In could be a default of most of Facebook users. Kwok and Yu (2013) also found that the conversational style of messages on Facebook posted by businesses produced a greater number of "Likes" than the direct sales/marketing tone of the messages. In addition, the simpler form of these messages (i.e., status updates and photos rather than links or videos) yielded a stronger effect. Given these user preferences and the effectiveness of non-commercial style of posts on Facebook, the power of LBIS in a form of in-group eWOM seems promising.

This promotional strategy is particularly critical on SNS in that what friends do directly influences users. This peer influence is key to LBIS intention and behavior, such that people showed great willingness to disclose their location on Facebook when they perceived that their friends had also checked in at locations on Facebook, but this relationship was present only when the users had positive attitudes toward the location checking in on Facebook (Chang \& Chen, 2014). In other words, the peer influence would not be powerful to the actual behavior of LBIS on Facebook without users' prior experience with the action.

\section{Study limitations and future research directions}

Several study limitations must be noted. Despite novel findings, the present study did not rigorously test the potential theoretical paths involving the variables reported here. The present study could have tested three main variables - check-in motivations, privacy concerns, and mobile phone dependency and proficiency - as they showed partial pictures of the relationships in each set of the findings. This limitation is innate primarily because of the small sample size of the data from the present study to conduct the path analysis (Kline, 1998). The present study recruited only 148 students who had location check-in experience in addition to 107 of those who did not check in at locations on Facebook given the time of data collection. More than half of student participants in the present study reported that they have tagged locations on Facebook, which represents fairly well a growing popularity of the check-in activity on Facebook. However, the number was not sufficient to run a path analysis or structural equation modeling. This also calls for future research.

In addition, the study did not specifically ask the participants regarding the types of businesses or locations to check in on Facebook. Although most LBIS has business and marketing potential (e.g., Noulas et al., 2011), the actual information shared by LBIS via Facebook Check In is still under analysis. Depending on the types as well as valence of the information as a form of customer evaluations on certain places, the magnitude of this in-group eWOM will vary. Furthermore, the perceived credibility of the information among Facebook friends when LBIS via Facebook Check In happens will be a critical factor to determine the potential influence of viral marketing on Facebook.

\section{Conclusion}

Nonetheless, this study can bring attention to the advertising industry of the motivations of location check-in as one type of eWOM. If indeed the LBIS on Facebook via mobile phone can provide interpersonal promotion for those business places without cost, this could be a great opportunity for many businesses. The low probability of the influence of perceived privacy invasion on Facebook check-in could offer the industry helpful insight. 
Businesses could develop strategies that promote Facebook users' location check-in at an offline spot. Such short, simple, appropriate promotional information voluntarily created and shared by "friends" would be effectively viral because of people's low resistance to but high reception of the shared information by trusted sources (Chowdhury, Parvin, Weitenberner, \& Becker, 2006; Steffes \& Burgee, 2008). 


\section{Appendix}

\section{Tables}

Table A. 1

Correlations Matrix

\begin{tabular}{|c|c|c|c|c|c|c|c|}
\hline & (MPI) & (GPC) & (FPC) & $(\mathrm{ENJ})$ & $(\mathrm{COM})$ & (SD\&R) & (PA) \\
\hline $\begin{array}{l}\text { MPI } \\
M_{\text {users }}=4.30(1.02) \\
M_{\text {non-users }}=3.70(1.15)\end{array}$ & 1 & $.12^{+}$ & .03 & $.15^{*}$ & $.21^{* *}$ & $.13^{+}$ & .06 \\
\hline $\begin{array}{l}\text { GPC } \\
M_{\text {users }}=4.44(1.42) \\
M_{\text {non-users }}=4.68(1.26)\end{array}$ & $.21^{*}$ & 1 & $.60^{* * *}$ & $.15^{*}$ & .07 & .10 & $.21^{* *}$ \\
\hline $\begin{array}{l}\text { FPC } \\
M_{\text {users }}=4.42(1.43) \\
M_{\text {non-users }}=4.67(1.68)\end{array}$ & $.18^{*}$ & $.22^{*}$ & 1 & $.15^{*}$ & 13 & .10 & $.28^{* * *}$ \\
\hline $\begin{array}{l}\text { ENJ } \\
M_{\text {users }}=3.70(1.50) \\
M_{\text {non-users }}=2.83(1.85)\end{array}$ & -.02 & $-.14^{+}$ & .04 & 1 & $.36^{* * *}$ & $.57^{* * *}$ & $.51^{* * *}$ \\
\hline $\begin{array}{l}\mathrm{COM} \\
M_{\text {users }}=3.67(1.44) \\
M_{\text {non-users }}=2.93(1.34)\end{array}$ & $.27^{* *}$ & $.16^{*}$ & -.05 & $.28^{* *}$ & 1 & $.43^{* * t}$ & $.34^{* * s}$ \\
\hline $\begin{array}{l}\mathrm{SD} \& \mathrm{R} \\
M_{\text {users }}=2.60(1.41) \\
M_{\text {non-users }}=1.91(1.14)\end{array}$ & .12 & -.05 & -.10 & $.54^{* * *}$ & $.40^{* * *}$ & 1 & $.50^{* * *}$ \\
\hline $\begin{array}{l}\mathrm{PA} \\
M_{\text {users }}=3.55(1.35) \\
M_{\text {non-users }}=2.18(1.40)\end{array}$ & $.15^{+}$ & -.23 & $.15^{+}$ & $.23^{* *}$ & $.18^{*}$ & $.38^{* * * *}$ & 1 \\
\hline
\end{tabular}

The numbers on top refer to results for the students who have checked in at locations on Facebook $\left(n_{\text {users }}=148\right)$. The numbers on bottom refer to those for the students who have not checked in at locations on Facebook $\left(n_{\text {non-users }}=107\right)$. Standard deviations are reported in parentheses next to mean values under each variable in the column section.

${ }^{+}$Correlation is significant at the 0.01 level (1-tailed).

${ }^{*}$ Correlation is significant at the 0.01 level (1-tailed).

${ }^{* *}$ Correlation is significant at the 0.01 level (1-tailed).

*** Correlation is significant at the 0.001 level (1-tailed).

Mobile phone involvement (MPI); General online privacy concern (GPC); Privacy concern on Facebook (FPC); Enjoyment (ENJ); Commitment (COM);

Self development and reputation (SD\&R); Promotional agency (PA).

Table A.2

Multiple Regression Models Predicting LBIS Motivations in Comparison Between Prior Check-in All Cases $(N=255$,

top), Users Only ( $n=148$, middle), and Non-Users Only ( $n=107$, bottom) for Each Predictor

\begin{tabular}{|c|c|c|c|c|}
\hline \multirow[t]{2}{*}{ Predictor } & \multirow{2}{*}{$\frac{\text { Enjoyment }^{\mathrm{a}}}{\beta(\mathrm{SE})}$} & \multirow{2}{*}{$\frac{\text { Commitment }^{\mathrm{a}}}{\beta(\mathrm{SE})}$} & \multirow{2}{*}{$\begin{array}{l}\text { Self development and reputation }{ }^{\mathrm{a}} \\
\beta(\mathrm{SE})\end{array}$} & \multirow{2}{*}{$\begin{array}{l}\text { Promotional agency } \\
\beta(\mathrm{SE})\end{array}$} \\
\hline & & & & \\
\hline General online privacy concern & $\begin{array}{l}-.05(.08) \\
.12(.09) \\
-.29^{+}(.15)\end{array}$ & $\begin{array}{l}.05(.07) \\
.01(.09) \\
.13(.11)\end{array}$ & $\begin{array}{l}-.01(.06) \\
.03(.09) \\
-.06(.09)\end{array}$ & $\begin{array}{l}-.10(.07) \\
.10(.08) \\
-.34^{*}(.11)\end{array}$ \\
\hline Facebook privacy concern & $\begin{array}{l}.05(.07) \\
.06(.09) \\
.06(.11)\end{array}$ & $\begin{array}{l}-.03(.06) \\
.07(.09) \\
-.11(.08)\end{array}$ & $\begin{array}{l}.00(.06) \\
.10(.08) \\
-.08(.07)\end{array}$ & $\begin{array}{l}.16^{*}(.06) \\
.21^{*}(.08) \\
.16^{+}(.08)\end{array}$ \\
\hline Mobile phone involvement & $\begin{array}{l}.12(.10) \\
.16(.12) \\
-.02(.16) \\
F=.73 \\
d f=3 / 251 \\
\text { Adjusted } R^{2}=.00 \\
F=1.90 \\
d f=3 / 144 \\
\text { Adjusted } R^{2}=.01 \\
F=1.33 \\
d f=3 / 103 \\
\text { Adjusted } R^{2}=.04\end{array}$ & $\begin{array}{l}.36^{* * *}(.08) \\
.29^{*}(.11) \\
.30^{* *}(.11) \\
F=7.63 \\
d f=3 / 251 \\
\text { Adjusted } R^{2}=.07^{*} \\
F=2.59 \\
d f=3 / 144 \\
\text { Adjusted } R^{2}=.03^{+} \\
F=3.61 \\
\text { df }=3 / 103 \\
\text { Adjusted } R^{2}=.07^{*}\end{array}$ & $\begin{array}{l}.23^{* *}(.08) \\
.18^{+}(.00) \\
.14(.10) \\
F=3.01 \\
d f=3 / 251 \\
\text { Adjusted } R^{2}=.02^{*} \\
F=1.83 \\
d f=3 / 144 \\
\text { Adjusted } R^{2}=.02 \\
F=1.12 \\
d f=3 / 103 \\
\text { Adjusted } R^{2}=.00\end{array}$ & $\begin{array}{l}.28^{* *}(.08) \\
.04(.11) \\
.23^{+}(.11) \\
F=6.12 \\
d f=3 / 251 \\
\text { Adjusted } R^{2}=.06^{*} \\
F=4.55 \\
d f=3 / 144 \\
\text { Adjusted } R^{2}=.07^{* *} \\
F=4.75 \\
d f=3 / 103 \\
\text { Adjusted } R^{2}=.10^{* *}\end{array}$ \\
\hline
\end{tabular}

${ }^{+} p<.10,{ }^{*} p<.05,{ }^{* *} p<.01,{ }^{* * *} p<.001$.

${ }^{a}$ Nov et al., 2009.

${ }^{\mathrm{b}}$ Henning-Thurau et al., 2004. 
Table A.3

Independent Samples T-tests for Facebook Check-Ins

\begin{tabular}{|c|c|c|c|c|}
\hline Dependent measure & Facebook check-in experience & Mean & S.D. & t-test (df) \\
\hline Mobile Phone Involvement & $\begin{array}{l}\text { Yes } \\
\text { No }\end{array}$ & $\begin{array}{l}4.29 \\
3.70\end{array}$ & $\begin{array}{l}1.02 \\
1.15\end{array}$ & $4.39(253)^{* * *}$ \\
\hline General Online Privacy Concern & $\begin{array}{l}\text { Yes } \\
\text { No }\end{array}$ & $\begin{array}{l}4.43 \\
4.68\end{array}$ & $\begin{array}{l}1.32 \\
1.26\end{array}$ & $-1.44(253)$ \\
\hline Facebook Privacy Concern & $\begin{array}{l}\text { Yes } \\
\text { No }\end{array}$ & $\begin{array}{l}4.42 \\
4.67\end{array}$ & $\begin{array}{l}1.43 \\
1.68\end{array}$ & $-1.28(253)$ \\
\hline Facebook Check-in Motivation: Enjoyment & $\begin{array}{l}\text { Yes } \\
\text { No }\end{array}$ & $\begin{array}{l}3.37 \\
2.87\end{array}$ & $\begin{array}{l}1.50 \\
1.85\end{array}$ & $2.58(198)^{*}$ \\
\hline Facebook Check-in Motivation: Commitment & $\begin{array}{l}\text { Yes } \\
\text { No }\end{array}$ & $\begin{array}{l}3.67 \\
2.93\end{array}$ & $\begin{array}{l}1.44 \\
1.34\end{array}$ & $4.17(253)^{* * *}$ \\
\hline Facebook Check-in Motivation: Self development and reputation & $\begin{array}{l}\text { Yes } \\
\text { No }\end{array}$ & $\begin{array}{l}2.59 \\
1.91\end{array}$ & $\begin{array}{l}1.40 \\
1.15\end{array}$ & $4.17(249)^{* * *}$ \\
\hline Facebook Check-in Motivation: Promotional agency & $\begin{array}{l}\text { Yes } \\
\text { No }\end{array}$ & $\begin{array}{l}3.55 \\
2.18\end{array}$ & $\begin{array}{l}1.35 \\
1.40\end{array}$ & $7.92(253)^{* * *}$ \\
\hline
\end{tabular}

$n_{\text {users }}=148 ; n_{\text {non-users }}=107$.

$+p<.10 ;{ }^{*} p<.05 ;{ }^{* *} p<.01 ;{ }^{* * *} p<.001$.

Table A.4

Summary of Binary Logistic Regression Analysis Predicting Likelihood of Location Check-Ins on Facebook by Location Check-In Motivations

\begin{tabular}{|c|c|c|c|c|}
\hline Predictor & $\mathrm{b}(\mathrm{SE})$ & Wald test $(d f)$ & $p$-value & Odds Ratios \\
\hline $\begin{array}{l}\text { LBIS Motivations } \\
\text { Enjoyment }^{\mathrm{a}}\end{array}$ & $.07(.11)$ & $.38(1)$ & .5356 & .94 \\
\hline Commitment $^{\mathrm{a}}$ & $.16(.12)$ & $1.67(1)$ & .1968 & 1.17 \\
\hline Self development and reputation ${ }^{a}$ & $.01(.15)$ & $.004(1)$ & .9488 & 1.01 \\
\hline Promotional agency ${ }^{\mathrm{b}}$ & $.70^{* * *}(.13)$ & $30.64(1)$ & $<.0001^{* * *}$ & 2.02 \\
\hline General online privacy concern & $-.16(.12)$ & $1.74(1)$ & .1876 & .85 \\
\hline Facebook privacy concern & $-.22^{*}(.11)$ & 4.31(1) & $.0378^{*}$ & .80 \\
\hline Mobile phone involvement & $.45^{* *}(.15)$ & $9.41(1)$ & $.0022^{* *}$ & 1.57 \\
\hline Constant & $-2.08(.80)$ & & $<.01^{* *}$ & \\
\hline \multicolumn{5}{|l|}{$\begin{array}{l}\text { Model } \chi^{2}=76.75, p<.0001 \\
R^{2}=.22\end{array}$} \\
\hline $\mathrm{N}=255$ & & & & \\
\hline
\end{tabular}




\section{Questionnaire items}

(All measures are on a 7-point scale)

\section{Mobile phone involvement}

(Walsh et al., 2010)

Please indicate the number that best reflects your opinion on each of the following items. I often think about my mobile phone when I am not using it. I often use my mobile phone for no particular reason.

Arguments have arisen with others because of my mobile phone use.

I interrupt whatever else I am doing when I am contacted on my mobile phone. I feel connected to others when I use my mobile phone.

I lose track of how much I am using my mobile phone.

The thought of being without my mobile phone makes me feel distressed.

I have been unable to reduce my mobile phone use.

\section{Consumers' privacy concern}

(Chellappa \& Sin, 2005)

Please indicate the number that best reflects your opinion on each of the following items.

I am sensitive about giving out information regarding my preferences.

I am concerned about anonymous information (information collected automatically but cannot be used to identify me, such as my computer, network information, operating system, etc.) that is collected about me.

I am concerned about how my personally unidentifiable information (information that I have voluntarily given out but cannot be used to identify me, e.g., Zip Code, age range, sex, etc.) will be used by the firm.

I am concerned about how my personally identifiable information (information that I have voluntarily given out AND can be used to identify me as an individual, e.g., name, shipping address, credit card or bank account information, social security number, etc.) will be used by the firm.

\section{Privacy concern on Facebook}

(Baek \& Morimoto, 2012)

If I check in on my Facebook, I am concerned about my privacy because...

I am concerned about misuse of personal information. I believe I will get unwanted

advertising material.

I believe that personal information is often misused.

I think companies share information without permission.

\section{Check-in motivations}

(Nov et al., 2009)

I find checkingin on Facebook to be enjoyable. (Enjoyment)

The process of checking in on Facebook is pleasant. (Enjoyment) I have fun checking in on Facebook. (Enjoyment) 
I would feel a loss if Facebook was no longer available. (Commitment)

I really care about the fate of Facebook. (Commitment) I feel a great deal of loyalty to Facebook.

(Commitment)

Checkingin publicly on Facebook gives me an opportunity to learn new things. (Self-development and reputation)

Checkingin publicly on Facebook enables me to become more proficient. (Self-development and reputation)

Checkingin publicly on Facebook enables me to enhance my expertise. (Self-development and reputation)

I earn respect for my online review expertise by checking in publicly on Facebook. (Selfdevelopment and reputation)

I feel that checking in publicly on Facebook improves my status as an online review expert. (Selfdevelopment and reputation)

I check in publicly on Facebook to improve my reputation as an online review expert. (Selfdevelopment and reputation)

Please indicate the number that best reflects your opinion on each of the following items. I check in a location on Facebook via my cell/ mobile phone because...

(Promotional agency motivations; Hennig-Thurau et al., 2004) I want to let people know where I am.

I want to tell people about a business or place I like. I want to promote an

item/business/service/place.

I want my friends to see a comment I have about a place.

I want to help others with my own positive experience with the location.

I want to give others the opportunity to have a good experience with the location.

This way I can express my joy about a good experience with the location.

I feel good when I can tell others about my great experience with the location.

I am so satisfied with the experience with the location that I want to help the location to be famous.

In my opinion, good companies/services/places should be supported.

\section{References}

Amblee, N., \& Bui, T. (2011). Harnessing the influence of social proof in online shopping: the effect of electronic word of mouth on sales of digital microproducts. International Journal of Electronic Commerce, 16(2), 91-113. http:// dx.doi.org/10.2753/JEC1086-4415160205.

Ames, M., \& Naaman, M. (2007). Why we tag: motivations for annotation in mobile and online media. In Proceedings of the SIGCHI conference on Human factors in computing systems (pp. 971-980). ACM. http://dx.doi.org/10.1145/ 1240624.1240772.

Baek, T., \& Morimoto, M. (2012). Stay away from me. Journal of Advertising, 41(1), 59-76. http://dx.doi.org/10.2753/JOA0091e3367410105.

Beldad, A., de Jong, M., \& Steehouder, M. (2011). A comprehensive theoretical framework for personal information-related behaviors on the Internet. The Information Society, 27, 220-232. http://dx.doi.org/10.1080/019722 43.2011.583802.

Bianchi, A., \& Phillips, J. G. (2005). Psychological predictors of problem mobile phone use. CyberPsychology \& Behavior, 8(1), 39-51. http://dx.doi.org/10.1089/ cpb.2005.8.39.

Bilogrevic, I., Huguenin, K., Mihaila, S., Shokri, R., \& Hubaux, J.-P. (2015). Predicting users' motivations behind location check-ins and utility implications of privacy protection mechanisms. 
In Proceedings of network and distributed system security (NDSS) symposium. Available from: http://infoscience.epfl.ch/record/202202/files/Bilogrevic2015NDSS_1.pdf.

Brandtzæg, P. B., Lüders, M., \& Skjetne, J. H. (2010). Too many Facebook "friends"? content sharing and sociability versus the need for privacy in social network sites. International Journal of HumanComputer Interaction, 26, 1006-1030. http://dx.doi.org/10.1080/10447318.2010.516719.

Chang, C.-W., \& Chen, G. M. (2014). College students' disclosure of location-related information on Facebook. Computers in Human Behavior, 35, 33-38. http:// dx.doi.org/10.1016/j.chb.2014.02.028.

Chang, C.-W., \& Heo, J. (2014). Visiting theories that predict college students' self-disclosure on Facebook. Computers in Human Behavior, 30, 79-86. http:// dx.doi.org/10.1016/j.chb.2013.07.059.

Chellappa, R. K., \& Sin, R. G. (2005). Personalization versus privacy: an empirical examination of the online consumer's dilemma. Information Technology and Management, 6, 181-202. http://dx.doi.org/10.1007/s10799-005-5879-y.

Chen, B., \& Marcus, J. (2012). Students' self-presentation on Facebook: an examination of personality and self-construal factors. Computers in Human Behavior, 28, 2091-2099. http://dx.doi.org/10.1016/j.chb.2012.06.013.

Chowdhury, H. K., Parvin, N., Weitenberner, C., \& Becker, M. (2006). Consumer attitude toward mobile advertising in an emerging market: an empirical study. International Journal of Mobile Marketing, 1(2), 33-42.

Christofides, E., Muise, A., \& Desmarais, S. (2009). Information disclosure and control on Facebook: are they two sides of the same coin or two different processes? CyberPsychology \& Behavior, 12, 341-345. http://dx.doi.org/10.1089/ cpb.2008.0226.

Debatin, B., Lovejoy, J. P., Horn, A. K., \& Hughes, B. N. (2009). Facebook and online privacy: attitudes, behaviors, and unintended consequences. Journal of Computer-Mediated Communication, 15(1), 83-108. http://dx.doi.org/10.1111/j.1083-6101.2009.01494.x.

Dwyer, C., Hiltz, S. R., \& Passerini, K. (2007). Trust and privacy concern within social networking sites: a comparison of Facebook and MySpace. In Proceedings of AMCIS 2007, Keystone, CO. Retrieved September 21, 2007 from http://csis.pace. edu/ dwyer/research/DwyerAMCIS2007.pdf.

Gilbert, G., \& Barton, H. (2013). The motivations and personality traits that influence Facebook usage. In A. Power, \& G. Kirwan (Eds.), Cyberpsychology and new media: A thematic reader (pp. 2637). New York, NY: Psychology Press.

Gruen, T. W., Osmonbekov, T., \& Czaplewski, A. J. (2006). eWOM: the impact of customer-tocustomer online know-how exchange on customer value and loyalty. Journal of Business Research, 59, 449-456. http://dx.doi.org/10.1016/ j.jbusres.2005.10.004.

Hennig-Thurau, T., Gwinner, K. P., Walsh, G., \& Gremler, D. D. (2004). Electronic word-of-mouth via consumer-opinion platform: what motivates consumers to articulate themselves on the Internet? Journal of Interactive Marketing, 18(1), 38-52. http://dx.doi.org/10.1002/dir.10073.

Hennig-Thurau, T., \& Walsh, G. (2003). Electronic word-of-mouth: motives for and consequences of reading customer articulations on the Internet. International Journal of Electronic Commerce, $8(2), 51-74$.

Huang, C.-H., \& Hsu, M.-C. (2013). Acceptance of location-based service technology - the Facebook check-in function. In Proceedings of the Service Systems and Service Management (ICSSSM) (pp. 809-812). IEEE. http://dx.doi.org/10.1109/ ICSSSM.2013.6602565.

Huang, C.-C., Lin, T.-C., \& Lin, K. J. (2009). Factors affecting pass-along email intentions (PAEIs): Integrating the social capital and social cognition theories. Electronic Commerce Research and Applications, 8(3), 160-169. http://dx.doi.org/ 10.1016/j.elerap.2008.11.001.

Hugl, U. (2011). Reviewing person's value of privacy of online social networking. Internet Research, 
21, 384-407. http://dx.doi.org/10.1108/10662241111158290.

Hung, K., Li, S. Y., \& Tse, D. K. (2011). Interpersonal trust and platform credibility in a Chinese multibrand online community. Journal of Advertising, 40(3), 103-116. http://dx.doi.org/10.2753/JOA0091-3367400308.

Jansen, B. J., Zhang, M., Sobel, K., \& Chowdury, A. (2009). Twitter power: tweets as electronic word of mouth. Journal of the American Society for Information Science and Technology, 60, 2169-2188. http://dx.doi.org/10.1002/asi.21149.

Jeong, E., \& Jang, S. S. (2011). Restaurant experiences triggering positive electronic word-of-mouth (eWOM) motivations. International Journal of Hospitality Management, 30, 356-366. http://dx.doi.org/10.1016/j.ijhm.2010.08.005.

Kim, H.-S., \& Sundar, S. S. (2011). Using interface cues in online health community boards to change impressions and encourage user contribution. In Proceedings of the 2011 annual conference on human factors in computing systems (CHI'11) (pp. 599-608). http://dx.doi.org/10.1145/1978942.1979028.

Kline, R. B. (1998). Principles and practice of structural equation modeling. New York: Guilford.

Kwok, L., \& Yu, B. (2013). Spreading social media messages on Facebook: an analysis of restaurant business-to-consumer communications. Cornell Hospitality Quarterly, 54(1), 84-94. http://dx.doi.org/10.1177/1938965512458360.

Lam, C. D., \& Mizerski, R. W. (2005). The effects of locus of control on word-of-mouth communication. Journal of Marketing Communications, 11, 215-228. http://dx.doi.org/10.1080/1352726042000333180.

Lindqvist, J., Cranshaw, J., Wiese, J., Hong, J., \& Zimmerman, J. (2011). I'm the mayor of my house: examining why people use foursquare-a social-driven location sharing application. In Proceedings of the SIGCHI conference on human factors in computing systems (pp. 2409-2418). ACM. http://dx.doi.org/10.1145/ 1978942.1979295.

Ljepava, N., Orr, R. R., Locke, S., \& Ross, C. (2013). Personality and social characteristics of Facebook non-users and frequent users. Computers in Human Behavior, 29, 1602-1607. http://dx.doi.org/10.1016/j.chb.2013.01.026.

Morrison, P. J. (2008). Tagging and searching: search retrieval effectiveness of folksonomies on the World Wide Web. Information Processing and Management, 44, 1562-1579.

Nakamoto, R. Y., Kakajima, S., Miyazaki, J., Uemura, S., Kato, H., \& Inagaki, Y. (2008). Reasonable tagbased collaborative filtering for social tagging systems. In Proceedings of the 2008 ACM conference on WICOW (pp. 11-18). ACM. http:// dx.doi.org/10.1145/1458527.1458533.

Noulas, A., Scellato, S., Mascolo, C., \& Pontil, M. (2011). An empirical study of geographic user activity patterns in foursquare. In ICWSM, 11, 70-573.

Nov, O., Naaman, M., \& Ye, C. (2009). Analysis of participation in an online photo-sharing community: a multidimensional perspective. Journal of the American Society for Information Science and Technology, 61, 555-566. http://dx.doi.org/ 10.1002/asi.21278.

Paradise, A., \& Sullivan, M. (2012). Visible threats? the third-person effect in perceptions of the influence of Facebook. Cyberpsychology Behavior and Social Networking, 15(1), 55-60. http://dx.doi.org/10.1089/cyber.2011.0054.

Perloff, R. M. (2009). Mass media, social perception, and the third-person effect. In J. Bryant, \& M. B. Oliver (Eds.), Media effects: Advances in theory and research (pp. 252-268). New York, NY: Routledge.

Petronio, S. (2002). Boundaries of privacy: Dialectics of disclosure. Albany: State University of New York Press.

Petronio, S. (2007). Translational research endeavors and the practices of communication privacy management. Journal of Applied Communication Research, 35, 218-222. http://dx.doi.org/10.1080/00909880701422443.

Pew Internet Research. (2013). Mobile technology fact sheet. Retrieved March 29, 2014, from 
http://www.pewinternet.org/fact-sheets/mobile-technology-fact-sheet/.

Pew Research Center. (2010). Millenials: A portrait of generation next. Retrieved July 2014 from http://www.pewsocialtrends.org/files/2010/10/millennials-confident-connected-open-tochange.pdf.

Phelps, J. E., Lewis, R., Mobilio, L., Perry, D., \& Raman, N. (2004). Viral marketing or electronic word-of-mouth advertising: examining consumer responses and motivations to pass along email. Journal of Advertising Research, 44, 333-348.

Pontes, T., Vasconcelos, M., Almeida, J., Kumaraguru, P., \& Almeida, V. (2012). We know where you live: privacy characterization of foursquare behavior. In Proceedings of the 2012 ACM conference on ubiquitous computing (pp. 898-905). ACM. http://dx.doi.org/10.1145/2370216.2370419.

Steffes, E. M., \& Burgee, L. E. (2008). Social ties and online word of mouth. Internet Research, 19(1), 42-49. http://dx.doi.org/10.1108/10662240910927812.

Sundar, S. S. (2008). Self as source: agency and customization in interactive media. In E. Konijn, S. Utz, M. Tanis, \& S. Barnes (Eds.), Mediated interpersonal communication (pp. 58-74). New York: Routledge.

Sun, T., Youn, S., Wu, G., \& Kuntaraporn, M. (2006). Online word-of-mouth (or mouse): an exploration of its antecedents and consequences. Journal of Computer-Mediated Communication, 11(4), 1104-1127. http://dx.doi.org/10.1111/ j.1083-6101.2006.00310.x.

Taddicken, M. (2014). The 'privacy paradox' in the social web: the impact of privacy concerns, individual characteristics, and the perceived social relevance on different forms of self-disclosure.
Journal
of Computer-Mediated
Communication,
19 ,
248-273. http://dx.doi.org/10.1111/jcc4.12052.

Walsh, S. P., White, K. M., \& Young, R. M. (2010). Needing to connect: the effect of self and others on young people's involvement with their mobile phones. Australian journal of psychology, 62(4), 194-203. http://dx.doi.org/10.1080/00049530903567229.

Wang, S. S. (2013). "I share, therefore I am": personality traits, life satisfaction, and Facebook check-ins. Cyberpsychology, Behavior, and Social Networking, 16, 870-877. http://dx.doi.org/10.1089/cyber.2012.0395.

Wang, S. S., \& Stefanone, M. A. (2013). Showing off? Human mobility and the interplay of traits, self-disclosure, and Facebook check-ins. Social Science Computer Review, 31, 437-457. http://dx.doi.org/10.1177/0894439313481424.

Waters, S., \& Ackerman, J. (2011). Exploring privacy management on Facebook: motivations and perceived consequences of voluntary disclosure. Journal of Computer-Mediated Communication, 17(1), 101-115. http://dx.doi.org/10.1111/ j.1083-6101.2011.01559.x.

Wathen, C. N., \& Burkell, J. (2002). Believe it or not: factors influencing credibility on the web. Journal of American Society for Information Science and Technology, 53, 134-144. http://dx.doi.org/10.1002/asi.10016.

Wilson, M. (2012). Location-based services, conspicuous mobility, and the location-aware future. Geoforum, 43, 1266-1275. http://dx.doi.org/10.1016/j.geofor um.2012.03.014.

Young, D. (2000). Location-based Services: Not ready for prime time, Wireless Review. Primedia Business Magazines \& Media Inc.

Yun, H., Han, D., \& Lee, C. C. (2013). Understanding the use of location-based service applications: do privacy concerns matter? Journal of Electronic Commerce Research, 14, 215-230.

Zhang, Y., \& Leung, L. (2014). A review of social networking service (SNS) research in communication journals from 2006 to 2011. New Media \& Society, 1, 1-18. http://dx.doi.org/10.1177/1461444813520477. 